\title{
Epidemiological study of ulcerative proctocolitis in Indian migrants and the indigenous population of Leicestershire
}

\author{
C S J Probert, V Jayanthi, D Pinder, A C Wicks, J F Mayberry
}

\begin{abstract}
A retrospective epidemiological study of ulcerative colitis (UC) and proctitis was performed in Leicestershire from 1972-89. Potential cases were identified from hospital departments of pathology, endoscopy, and medical records and from general practitioners. The county population includes more than 93000 South Asians. There were 573 cases of UC and 286 of proctitis in Europeans and 115 cases of UC and 29 of proctitis in South Asians. The standardised incidence of UC in Europeans and South Asians was stable, except in Sikhs in whom it had increased rapidly. The relative risk of UC to South Asians was 2.45. The standardised incidences of UC in South Asians during the 1980s were: $10 \cdot 8 / 10^{5} /$ year in Hindus $(95 \%$ confidence interval (CI) 7.4-14.1 cases/10\% year) $16 \cdot 5 / 10^{5} /$ year in Sikhs $(95 \%$ CI 7.9-25.2 cases $/ 10^{5} /$ year), and $6 \cdot 2 / 10^{5} /$ year in Muslims (95\% CI 1.6-10.9 cases/10 $/$ year). There was no difference in incidence between Asians from East Africa and India. The standardised incidence of UC in Europeans was 5.3/10\% year (95\% CI $4 \cdot 3-6 \cdot 3$ cases $/ 10^{5} /$ year). The standardised incidences of proctitis were $3 \cdot 1$ / $10^{5} /$ year (95\% CI $1.9-2.5$ cases $/ 10^{5} /$ year) in South Asians and 2.3/10 $/$ year (95\% CI 1.8-2.4 cases $/ 10^{5} /$ year) in Europeans. Ethnic groups had a similar disease distribution, except Sikhs in whom it was less extensive. Despite the similar disease distribution, South Asians had fewer operations and complications from UC than Europeans. There was a bimodal age specific incidence in Europeans, but not in other ethnic groups. First and second generation South Asians were at similar risk. Hindus and Sikhs have a significantly higher incidence of UC than Europeans in Leicestershire.
\end{abstract}

Epidemiological studies have shown noticeable regional variations in the incidence of ulcerative colitis (UC). Most studies have been performed in westernised countries ${ }^{1-10}$ and there are few reliable data from UC in Asia. ${ }^{11-16}$ Hospital based studies have suggested that UC is rare, although a recent report from India has questioned this. ${ }^{17}$ When people migrate the diseases they develop may result from exposure to different environmental factors. Consequently the study of migrants can be useful in the evaluation of aetiological factors in disease.

There are now about 1.2 million South Asian people living in Britain. 18 'South Asian' refers to people whose families originated from India,
Pakistan, or Bangladesh. ${ }^{1920}$ Although there have been clinical reports of the disease, there have been few epidemiological studies of inflammatory bowel disease among South Asians in Britain. ${ }^{21-24}$ Most suggest the incidence of UC is either similar or lower than that in the indigenous population. ${ }^{21} 22$

Migrants of South Asian descent began to settle in the city of Leicester in the late 1950s. However, most came in the late 1960s and early 1970s. They were split equally between those born in India and those from East Africa. The latter group arrived after the Africanisation policy of newly independent nations in East Africa was introduced. ${ }^{25}$ Sixty seven per cent of South Asians in Leicester are of Gujarati descent and mostly Hindu. ${ }^{26}$ Punjabis are the second largest South Asian group, most are Sikh. The rest of the South Asian community in Leicester is made up of Muslims from Gujarat, Punjab, and Pakistan. There are few Bangladeshi Muslims or Parsees in the county.

Leicestershire is an ideal area for epidemiological studies among South Asian migrants because of its large population. It is served by one health authority. The four largest hospitals in the county are all in the city of Leicester and patients attend these for invasive procedures and major surgery. People on the boundary of the county may be referred to other districts for investigation and treatment.

The aim of this study was to determine the epidemiology of UC and proctitis in the county of Leicestershire and compare incidence in the indigenous population with that in South Asians.

\section{Patients and methods}

IDENTIFICATION AND DEFINITION OF CASES

The study was performed retrospectively from 1 January 1972 to 31 December 1989, inclusive. Potential cases were identified from both hospital and general practice sources. Disease registers of general practitioners throughout the county and of adjoining counties whose catchment area crossed into Leicestershire were reviewed, as well as records held in pathology and endoscopy departments, hospital activities analysis (HAA) and Korner data from the Leicestershire Health Authority. In addition, personal registers (ACW and JFM) were examined and consultants in private practice asked to identify patients with inflammatory bowel disease. People from Leicestershire treated in adjoining districts were identified from the records held by Oxfordshire, Trent, and East Anglia Regional Health Authorities (HAA and Korner data). Finally, 
supraregional referrals were identified from Birmingham, Oxford, and London. Case notes and microfiche records were obtained for all potential cases. The two private hospitals in the district do not have facilities to identify patients treated with inflammatory bowel disease, but such cases were identified directly from either general practitioners or specialists in private practice.

For all candidates, demographic details and the results of laparotomy, histopathological, microbiological, radiological, and endoscopic investigations were noted. All potential cases were reviewed by two of the authors (VJ and CSJP) using a structured proforma (Appendix I) and inter- and intraobserver variation was assessed. Patients in whom the diagnosis of UC was entirely clinical were excluded. Cases of Crohn's colitis and indeterminate colitis, defined as continuous inflammatory disease limited to the colon with equivocal histological or endoscopic appearances, were analysed separately. Microbiological tests were reviewed when available and those patients with a positive stool culture were excluded (stool culture is routinely performed in Leicestershire because of the possibility of South Asian patients becoming infected during travel overseas). Patients with secondary colitis as a result of ischaemia or radiation were also excluded, as were those with apparent acute self limiting colitis. Only patients diagnosed while residing in the county during the study period were included in the incidence study.

\section{CASE DEFINITION}

UC was defined as idiopathic continuous colitis, and proctitis as idiopathic disease confined to the rectum. Those in whom the upper limit of the disease was not delineated were defined as UC. Secondary colitis was specifically excluded.

The same criteria were used throughout the study and for all ethnic groups: a proforma was used to ensure uniformity. An acceptable clinical history of passage of blood and mucus per rectum with or without diarrhoea, with characteristic endoscopic, histological, or radiological findings was essential to the diagnosis. Endoscopic and radiological features required for the diagnosis were continuous disease with superficial ulceration or lack of haustrations. Histological features included superficial inflammation with goblet cell depletion and an absence of granulomas or lymphoid aggregates. All histology reports for each patient were reviewed. A sample of histology slides was reviewed by an independent pathologist and the diagnosis confirmed.

An important and integral part of the definition of UC and proctitis is their recurrent nature. Patients with single attacks consistent with acute self limiting colitis were specifically excluded. Persistent or recurrent symptoms after a follow up of at least one year were an essential requirement for the diagnosis of ulcerative colitis or proctitis to be accepted. Consequently, the last date of diagnosis for inclusion in the study was 31 December 1989, with all cases reviewed until the end of 1990.

\section{DEFINITION OF POPULATION}

Leicestershire comprises the city of Leicester (population approximately 280000 of whom 75000 were South Asian), its adjoining suburbs, several large towns, and a large rural area. The county as a whole has a population of 930600 , of whom 93401 are South Asian. Thus, 81\% of South Asians in the county live within the city boundary. There are seven towns which have populations of about 10000 or greater: Loughborough (population 51889), Coalville (population 29472), Hinckley (population 26 335), Melton Mowbray (population 23509 , Market Harborough (population (23 509), Ashby de la Zouch (population 10887), and Oakham (9961). The definition of the truly rural population used in this study were those people living outside the city of Leicester, its suburbs, and these seven towns (304 760).

Population data were obtained from a variety of sources: Office of Population Censuses and Surveys (OPCS), 1971 and 1981; $;^{2728}$ Leicester Council for Community Relations, 1978 and $1982 ;{ }^{29}$ Survey of Leicester, $1983 ; ;^{25}$ Leicestershire County Council ${ }^{30}$ and Leicester City Council projections, 1990 (personal communication); and Family Health Services Authority (FHSA), 1990 (personal communication). The European population remained relatively constant, the mean of the OPCS from 1971 and 1981 was used for incidence calculations during the 1970 s, the means of the OPCS (1981) estimate and the Leicestershire County Council projection (1989) were used in a similar manner. The South Asian population grew rapidly during the late 1960 s and early 1970s; the population estimates from all the sources listed were used to construct a table of population size by age and year of description from which the mean populations during the 1970s and 1980s were found. The table was used in a similar way to calculate the age specific incidence for each year. The sources used made particular reference to South Asians and by combining estimates in this way inaccuracies for individual sources were minimised.

From raw data of 930000 people registered with the FHSA, an age-sex analysis for the following religious groups: Hindus, Sikhs, Muslims, and others (principally Christians) was performed. Surnames were scrutinised by one European and four South Asian investigators, surnames were used to place people in religious groups. Such use of surnames to define religion is reliable for South Asians $s^{3132}$ and the data thus obtained can be used with confidence as $98 \%$ of the community is registered with a general practitioner. ${ }^{33}$ Very few South Asian migrants intermarry ${ }^{34}$ (Indians (1·3\%), Pakistani $(6 \cdot 7 \%)$, and Bangladeshi $(0 \%)$ ) and consequently the population figures obtained from surname analysis accurately reflect the true size of the community.

The ethnic mix of the City of Leicester has been described in various reports, the most accurate of which is the Survey of Leicester, $1983,{ }^{25}$ which was based on a survey of 16700 households. The ethnic mix for the county has been examined by place of birth of head of household (OPCS 1981), ${ }^{28}$ but not by religious 
group. Data based on FHSA registration have provided ethnic mix data for the whole county. From a knowledge of the proportion of South Asians in the county who reside in the city, their ethnic composition was estimated. Thus, there are several accurate estimates of the size of ethnic groups in the city of Leicester, but only one estimate for the county. Extrapolation of city data to the whole county may be flawed, so the incidence in different South Asian religious groups has only been compared within the city.

\section{CALCULATIONS}

The date of definitive diagnosis was used for incidence calculations. Data were analysed using a modified Cochran's test to compare standardised incidences, ${ }^{35}$ a $\mathrm{Z}$ statistic for populations, ${ }^{35} \mathrm{X}^{2}$ test, relative risk for population studies, and $95 \%$ confidence intervals (CI). ${ }^{36}$ The latter were performed using Confidence Interval Analysis software. Standardisation, by age, used the whole population of the county of Leicestershire.

The underlying null hypothesis throughout the study and calculations was that the incidence of UC is the same in Europeans and South Asians and that the incidence is stable.

Ethical committee approval was given for the study.

\section{Results}

Over 2500 potential cases of inflammatory bowel disease were scrutinised, of whom 1420 had ulcerative proctocolitis and 807 Crohn's disease. The remainder has been miscoded as a result of discussions about differential diagnosis which were filed in case notes. Irritable bowel syndrome, ischaemic colitis, and diverticular disease were among the most commonly miscoded diagnosis.

TABLE I Cases and incidence (cases/100000 year) of ulcerative colitis in the city of Leicester

\begin{tabular}{|c|c|c|c|c|c|}
\hline \multirow[t]{2}{*}{ Year } & \multicolumn{5}{|l|}{ No of cases } \\
\hline & European & South Asian & $H$ indu & Sikh & Muslim \\
\hline 1972 & 11 & 2 & 2 & & \\
\hline 1973 & 11 & 3 & 2 & & 1 \\
\hline 1974 & 5 & 2 & 2 & & \\
\hline 1975 & 9 & 6 & 5 & & 1 \\
\hline 1976 & 5 & 3 & 3 & & \\
\hline 1977 & 5 & 7 & 7 & & \\
\hline 1978 & 5 & 3 & 2 & & 1 \\
\hline 1979 & 12 & 6 & 5 & & $\mathrm{i}$ \\
\hline 1980 & 12 & 6 & 6 & & \\
\hline \multicolumn{6}{|l|}{$\begin{array}{c}\text { Standardised } \\
\text { incidence }\end{array}$} \\
\hline$(1972-80)$ & 3.6 & $9 \cdot 3$ & $13 \cdot 4$ & 0 & $4 \cdot 6$ \\
\hline $95 \% \mathrm{CI}$ & $2 \cdot 7-4 \cdot 2$ & $6 \cdot 4-12 \cdot 2$ & $8 \cdot 9-17 \cdot 9$ & 0 & $0 \cdot 1-9 \cdot 2$ \\
\hline 1981 & 19 & 6 & 5 & & 1 \\
\hline 1982 & 15 & 1 & 1 & & \\
\hline 1983 & 8 & 10 & 7 & 2 & 1 \\
\hline 1984 & 11 & 6 & 5 & & 1 \\
\hline 1985 & 13 & 11 & 8 & 2 & 1 \\
\hline 1986 & 8 & 9 & 6 & 2 & 1 \\
\hline 1987 & 6 & 6 & 4 & 1 & 1 \\
\hline 1988 & 15 & 6 & i & 5 & \\
\hline 1989 & 10 & 6 & 3 & 2 & 1 \\
\hline \multicolumn{6}{|l|}{$\begin{array}{c}\text { Standardised } \\
\text { incidence }\end{array}$} \\
\hline (1981-89) & $5 \cdot 3$ & $10 \cdot 8$ & $10 \cdot 8$ & $16 \cdot 5$ & $6 \cdot 2$ \\
\hline $95 \% \mathrm{CI}$ & $4 \cdot 3-6 \cdot 3$ & $8 \cdot 0-13 \cdot 4$ & $7 \cdot 4-14 \cdot 1$ & $7 \cdot 9-25 \cdot 2$ & $1.6-10 \cdot 9$ \\
\hline
\end{tabular}

The incidence of ulcerative colitis in Europeans and South Asians increased significantly from the 1970 s to the 1980 s. Hindus were at significantly greater risk than Europeans $(Z=3 \cdot 0, p<0 \cdot 01$ during the $1970 \mathrm{~s}$ and $Z=2 \cdot 0, p<0 \cdot 05$ in the $1980 \mathrm{~s}$ ). Sikhs were at significantly greater risk during the $1980 \mathrm{~s}$, $\mathrm{z}=3.9, \mathrm{p}<0 \cdot 001)$.
Most candidate cases were identified through hospital based sources, 119 cases $(5 \cdot 3 \%)$ were identified from general practitioners alone, although all had been treated in Leicestershire hospitals.

Intraobserver variation was assessed at the beginning of the study, with one discrepancy among 20 cases rechecked by CSJP and one of 25 cases rechecked by $\mathrm{VJ}$. When intraobserver variability was reassessed at the end of the study no discrepancies were found. Interobserver variation was assessed throughout the study. Randomly selected cases were compared and only in one of 180 cases reviewed by both reviewers (CSJP and VJ) was there disagreement about diagnosis; the case was subsequently classified as indeterminate colitis. These three assessments are not entirely comparable and reflect a small learning curve, with most disagreement at the beginning of the study.

Altogether, 691 cases of UC and 321 of proctitis were diagnosed in the county between 1972 and 1989, the 408 remaining cases were diagnosed either before 1972 or after 1989.

\section{INCIDENCE}

\section{Ulcerative colitis}

Leicester city: Between 1972 and 1980 there were 75 new cases of UC in Europeans and 38 in South Asians among the 278000 people living in the city. Of the South Asians, 34 were Hindu and 4 Muslim (Table I). South Asians had significantly more UC than Europeans $(z=1 \cdot 96$, $\mathrm{p}<0.05)$. The excess was among Hindus, in whom the standardised incidence was $13 \cdot 4 / 10^{5} /$ year $(z=1.98, p<0.05)$. The relative risk to Hindus was 3.9. The standardised incidence in Muslims was similar to that in Europeans $(z=1 \cdot 4$ NS).

From 1981 to 1989 there were 105 cases in Europeans and 61 in South Asians, of whom 40 were Hindu, 7 Muslim, and 14 Sikh. The standardised incidence in Europeans had risen significantly $\left(\mathrm{X}^{2}=8.5, \mathrm{p}<0.005\right)$ to $5.3 / 10^{5} /$ year, while in South Asians the standardised incidence was stable $\left(\mathrm{X}^{2}=0.6\right)$ at $10 \cdot 8 / 10^{5} /$ year. However, South Asians still had significantly more UC than Europeans $(z=2 \cdot 15, p<0 \cdot 05)$. The Hindus and Sikhs had significantly more UC than Europeans $(Z=2 \cdot 0, \quad \mathrm{p}<0.05$ and $Z=3.9$, $\mathrm{p}<0.001$ respectively). The relative risk to all South Asians was 2.45 and to Hindus and Sikhs 1.9 and 2.9 respectively. The standardised incidence in Muslims was again similar to Europeans.

Of the 99 South Asians, 77 were first generation migrants. As there are no accurate data on the population size of first and second generations, the incidence in these groups cannot be estimated. However, most second generation South Asians are under 20 years old and the population at risk is probably still relatively small (see section on age specific incidence).

County incidence: Data from the city of Leicester were used with those from the rest of the county. During the 1970s there were 282 cases of UC in Europeans and 46 in South Asians (Table II). South Asians had a significantly 


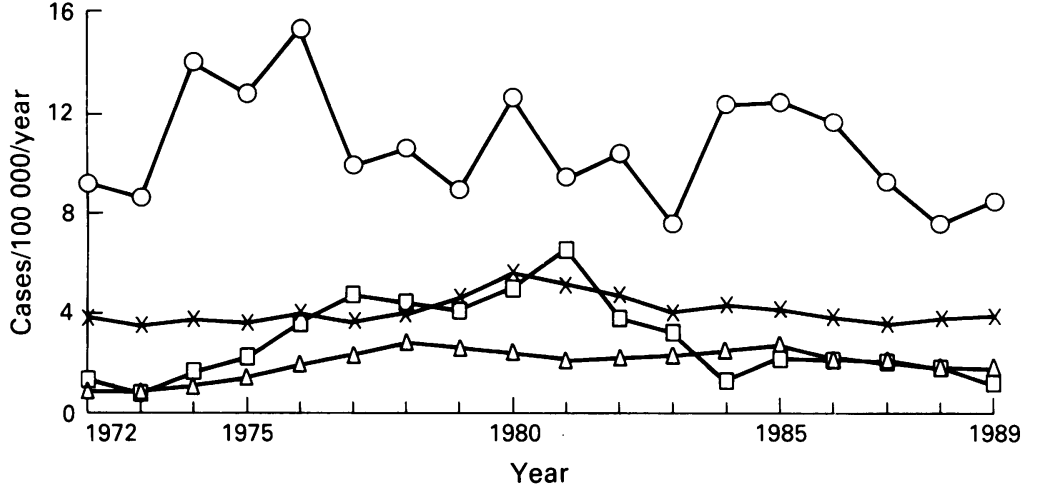

$\triangle$ European proctitis $\square$ Asian proctitis $x$ European colitis $\bigcirc$ Asian colitis

Figure 1: Age standardised incidence of ulcerative colitis and proctitis in the county of Leicestershire. The age standardised incidence of ulcerative colitis and proctitis was calculated for each ethnic group for each year of the study. The rolling incidence, shown on the graph, was found using the mean incidence for each disease over three year periods, for example, '1976' was calculated from 1975-77 and '1977' from 1976-78.

greater standardised incidence than Europeans $(\mathrm{Z}=3 \cdot 7, \mathrm{p}<0.001)$.

The standardised incidence of UC in Europeans remained constant in the 1980 s at 4.38 cases $/ 10^{5} /$ year. The standardised incidence in South Asians fell marginally to 9.95 cases/10\% year and they remained at significantly greater risk of UC than Europeans $(Z=3.5 p<0.001)$ (Fig 1). The fall in standardised incidence in South Asians was not statistically significant $\left(\mathrm{X}^{2}=0 \cdot 45\right)$.

There was no difference in the incidence of UC in South Asians arriving from East Africa or India $(Z=1 \cdot 4 \mathrm{NS})$.

\section{Proctitis}

In Leicestershire there were 126 cases in Europeans (standardised incidence $1.8 \mathrm{cases} / 10^{5} /$ year) and 14 in South Asians (standardised incidence 3.0 cases $/ 10^{5} /$ year) during the $1970 \mathrm{~s}$.

TABLE II Incidence of ulcerative colitis in urban and rural areas in Europeans

\begin{tabular}{|c|c|c|c|c|}
\hline & \multicolumn{2}{|c|}{$1972-80$} & \multicolumn{2}{|c|}{$1981-9$} \\
\hline & Cases & Incidence & Cases & Incidence \\
\hline Leicester city & 75 & $3 \cdot 6$ & 105 & $5 \cdot 1$ \\
\hline Leicester suburbs & 47 & $5 \cdot 1$ & 30 & $3 \cdot 3$ \\
\hline \multicolumn{5}{|l|}{ Combined } \\
\hline incidence & 122 & $4 \cdot 1$ & 135 & $4 \cdot 3$ \\
\hline Seven towns & 50 & $3 \cdot 0$ & 42 & $2 \cdot 8$ \\
\hline Rural & 117 & $4 \cdot 3$ & 106 & $3 \cdot 9$ \\
\hline
\end{tabular}

There was no difference in the combined incidence for the city of Leicester and its suburbs and the incidence in rural areas during the $1970 \mathrm{~s}(Z=0.3 \mathrm{~ns})$ or during the $1980 \mathrm{~s}(Z=1.8 \mathrm{~ns})$.

TABLE III Means of diagnosis of ulcerative colitis in Leicestershire 1972-89

\begin{tabular}{lcc}
\hline & \multicolumn{2}{l}{ No $(\%)$ patients } \\
\cline { 2 - 3 } & Europeans & South Asians \\
\hline No histology & $18(3 \cdot 2 \%)$ & $1(0 \cdot 9)$ \\
Histology alone & $9(1 \cdot 6)$ & 0 \\
Radiology or endoscopy alone & $13(2 \cdot 3)$ & $2(1 \cdot 7)$ \\
Histology and radiology or & $511(90)$ & $107(90 \cdot 7)$ \\
\hline
\end{tabular}

The standardised incidence rose marginally, in Europeans to $2 \cdot 3$ cases $/ 10^{5} /$ year and in South Asians to $3 \cdot 14$ cases $/ 10^{5} /$ year in the 1980 s. There was no statistical difference between the incidence in each ethnic group during the $1970 \mathrm{~s}$ $(Z=0.6 \mathrm{NS})$ or the $1980 \mathrm{~s}(\mathrm{Z}=0.9 \mathrm{NS})$. The relative risk to South Asians during the 1970s and 1980 s were $1.9(95 \%$ CI $1 \cdot 1-3 \cdot 3)$ and 1.4 $(95 \%$ CI $0 \cdot 9-2 \cdot 2)$ respectively.

The change in incidence in each ethnic group, from the 1970s to 1980 s, was not significant $\left(\mathrm{X}^{2}=2 \cdot 7\right.$ and $0 \cdot 1$ for Europeans and South Asians respectively).

Incidence by urban-rural areas

The incidence of UC in the city of Leicester and its suburbs was $4 \cdot 1$ cases cases/ $10 \% /$ year compared with 4.3 cases $/ 10^{5} /$ year in the rural areas of the county $(Z=0.3 \mathrm{NS})$ in the $1970 \mathrm{~s}$. During the 1980 s the incidence in the city and its suburbs had risen to 4.9 cases $/ 10^{5} /$ year compared with a stable figure of 3.9 in rural areas $(Z=1.8 \mathrm{NS})$. There seems to be no significant difference in the frequency of UC in the urban and rural sectors of the county of Leicestershire.

\section{SEX RATIO AND AGE SPECIFIC INCIDENCE}

\section{Ulcerative colitis}

Both sexes were similarly affected in each ethnic group. The relative risk to men was 1.2 in Europeans $(95 \%$ CI $1-1 \cdot 4 ;, 1 \cdot 1$ in Hindus $(95 \%$ CI 0.7-1.6), 0.8 in Sikhs (95\% CI 0.3-2.0), and 2 $(95 \%$ CI 0.6-6.6) in Muslims.

\section{Proctitis}

In Europeans, both sexes were equally affected by proctitis, (relative risk to men $1.05,95 \% \mathrm{CI}$ $0 \cdot 8-1 \cdot 3)$. The CIs of relative risk in South Asian ethnic groups were wide, Hindus $0.67(95 \% \mathrm{CI}$ $0 \cdot 3-1 \cdot 5)$ and Sikhs $2 \cdot 5(95 \% \mathrm{CI} ; 0 \cdot 5-13)$. Of the Muslims, only three men and no women had proctitis. The width of these confidence intervals limits the value of any statistical comparison.

There was no association between age and age specific incidence of UC or proctitis in any ethnic group. Europeans show a bimodal age distribution, with the highest age specific incidence in those aged $71-75$ years (Fig 1). The age specific incidence was significantly increased in those aged $21-30$ years, 55-60 years, and 71-75 years. In South Asians the age specific incidence was significantly raised in those aged $21-30$ years. A bimodal pattern was not seen in South Asians. Furthermore, the South Asian age specific incidence suggests that first (older) and second generation (under 20 years old) South Asians are at similar risk of developing UC.

\section{INCIDENCE IN CHILDREN}

Ulcerative colitis

The incidence of UC in European children aged $0-10$ years was $0 \cdot 3$ cases $/ 10 \%$ year $(95 \%$ CI $0-0 \cdot 6 /$ 105 year) and did not change during the period of study. There were five cases in South Asian 


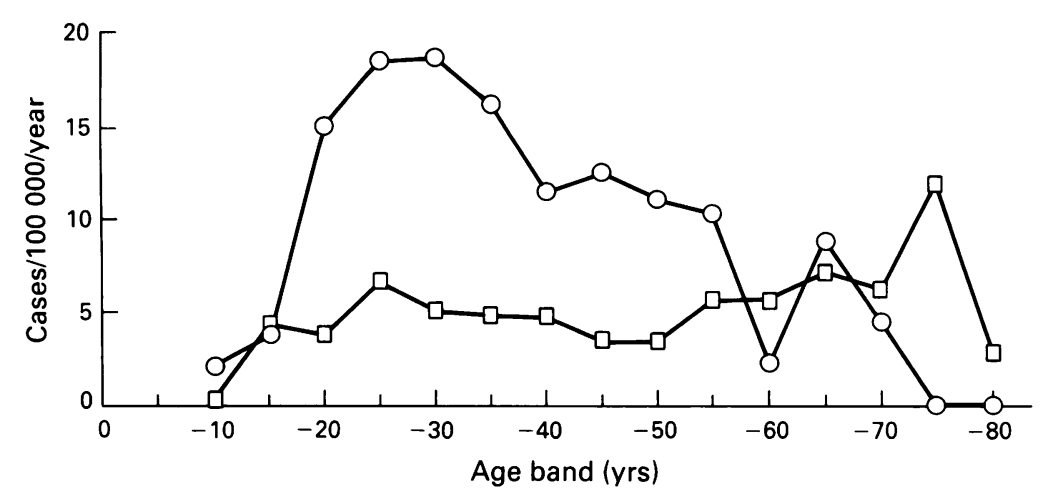

$\square$ Europeans OSouth Asians

Figure 2: Age specific incidence of ulcerative colitis in the city of Leicester. The age specific incidence was significantly increased in those aged 21-30 years, 55-60 years, and 71-75 years. In South Asians the age specific incidence was significantly raised in those aged 21-30 years.

The scale disguises the bimodal distribution in Europeans, a feature not seen in Europeans.

children in whom the incidence increased threefold from $1 \cdot 0$ cases $/ 10^{5} /$ year $\left(95 \%\right.$ CI $0 \cdot 3 \cdot 4 / 10^{5} /$ year) in the 1970 s to $2 \cdot 7$ cases $/ 10^{5} /$ year $(95 \%$ CI $0-5 \cdot 5 / 10^{5} / 10^{5} /$ year) in the $1980 \mathrm{~s}$. The incidence fell in European children aged 11-15 years, from $3 \cdot 3$ cases $/ 10^{5} /$ year $\left(95 \%\right.$ CI $1 \cdot 8-5 \cdot 4 / 10^{5} /$ year) in the 1970 s when there were 15 cases, to 1.5 cases/ $105 /$ year (95\% CI $0 \cdot 4-2 \cdot 9 / 10^{5} /$ year) in the 1980 s when there were seven cases. This change was not significant $\left(X^{2}=2 \cdot 9\right)$. The incidence in South Asian children of the same age also fell from $4 \cdot 7$ cases $/ 10^{5} /$ year $\left(95 \%\right.$ CI $0-10 \cdot 2 / 10^{5} /$ year $)$ to $3 \cdot 0$ cases $/ 10^{5} /$ year $\left(\mathrm{X}^{2}=0 \cdot 2\right)$.

All South Asian children with ulcerative colitis were born in Britain.

\section{Proctitis}

There were no cases in children aged less than 11 years old. The incidence in European children aged 11-15 years was constant at 0.4 cases $/ 10^{5}$ / year. There was only one case in a South Asian child during the $1980 \mathrm{~s}$, with an incidence of 0.9 cases $/ 10^{5} /$ year.

\section{DISEASE DIAGNOSIS}

Most patients (62\%) were diagnosed using information from three techniques; histology, radiology, and endoscopy. A further $26 \%$ were diagnosed using a combination of endoscopy and histology data (Table III).

There was no statistical difference in the means of diagnosis in Europeans and South Asians.

TABLE IV Disease distribution by ethnic group in the city of Leicester

\begin{tabular}{lrllll}
\hline \multicolumn{7}{l}{ No $(\%)$ patients } \\
\cline { 2 - 6 } & Proctitis & Distal colon & Transverse colon & Pancolitis & Not defined \\
\hline Europeans & $102(36)$ & $50(18)$ & $41(15)$ & $69(24)$ & $20(7)$ \\
South Asians: & $29(23)$ & $31(24)$ & $16(13)$ & $43(34)$ & $9(7)$ \\
Hindu & $20(21)$ & $23(24)$ & $10(10)$ & $36(38)$ & $5(5)$ \\
Sikhs & $6(30)$ & $8(40)$ & $2(10)$ & $1(5)$ & $3(5)$ \\
Muslims & $3(21)$ & 0 & $4(29)$ & $6(43)$ & $1(7)$ \\
\hline
\end{tabular}

The distribution of ulcerative colitis was similar in Europeans and South Asians $\left(X^{2}=2, N S\right)$. However, Sikhs have less extensive disease and Muslims more extensive disease $\left(\mathrm{X}^{:}=17 \cdot 4, \mathrm{p}<0.01\right)$ Although this difference is based on small absolute numbers, these findings may suggest Muslims present with more severe disease than Sikhs and Hindus.
TABLE $\mathrm{v}$ Published data on the incidence of ulcerative colitis in Europe

\begin{tabular}{|c|c|c|c|}
\hline & & & $\begin{array}{l}\text { Incidence } \\
\text { (cases/10'/year) }\end{array}$ \\
\hline Area of study & Duration & No cases & (inc proctitis) \\
\hline \multicolumn{4}{|l|}{ United Kingdom } \\
\hline Oxford' & $1951-60$ & 285 & $6 \cdot 7$ \\
\hline Scotland ${ }^{2}$ & $1967-76$ & 537 & $11 \cdot 3$ \\
\hline Cardiff ${ }^{3}$ & $1968-77$ & 277 & $7 \cdot 2$ \\
\hline High Wycombe + & $1975-84$ & 302 & $6 \cdot 5$ \\
\hline Leicestershire & $1972-89$ & 1012 & \\
\hline (1) Europeans & & 861 & $6 \cdot 0$ \\
\hline (2) South Asians & & 151 & $13 \cdot 9$ \\
\hline \multicolumn{4}{|l|}{ Denmark ${ }^{5}$} \\
\hline Copenhagen & $1962-78$ & 682 & $8 \cdot 1$ \\
\hline \multicolumn{4}{|l|}{ Germany ${ }^{6}$} \\
\hline Tubingen Co & $1970-84$ & 376 & $2 \cdot 0$ \\
\hline Finland Uppsala & $1965-83$ & 2509 & $10 \cdot 6$ \\
\hline Iceland & $1950-79$ & 318 & $7 \cdot 4$ \\
\hline Netherlands ${ }^{8}$ Leiden & $1979-83$ & 150 & $7 \cdot 0$ \\
\hline Sweden" Stockholm & $1955-79$ & 1274 & $4 \cdot 7$ \\
\hline
\end{tabular}

INCIDENCE BY DISEASE SITE

There was no difference in disease extent between Europeans and South Asians, $\left(\mathrm{X}^{2}=2, \mathrm{NS}\right)$ (Table IV).

There was no association between age and extent of disease.

\section{FREQUENCY OF SURGICAL MANAGEMENT}

The probability of resection was assessed by finding the number of resections/100 patient years for each ethnic group, from this proportion frequencies can be compared using CIs and the expected number of resections calculated to enable the $\mathrm{X}^{2}$ test to be used. South Asians had significantly fewer operations than Europeans $\left(\mathrm{X}^{2}=3.97 \mathrm{p}<0.05\right)$. For Europeans the resection rate $1 \cdot 7 / 100$ years and for South Asians $1 \cdot 1 / 100$ years at risk, the $\mathrm{CI}$ for the difference was $0 \cdot 14$ to $1 \cdot 2$. Both groups were equally likely to have ileoanal anastomosis after colectomy, $\left(\mathrm{X}^{2}=0 \cdot 69\right.$, NS).

\section{Discussion}

This is the first detailed study of the incidence of ulcerative colitis in South Asian migrants. The standardised incidence of true UC in South Asians in the city of Leicester and Leicestershire, (10 cases/10\%/year) is one of the highest in any population or region in the world. Analysis of different religious and ethnic groups in the city has shown that during the 1980s, Hindus and Sikhs were at greatest risk and the risk for Sikhs has risen sharply since 1982 . The incidence of proctitis in South Asians was stable (3.1 cases/ 10 /year). Reporting the incidence of UC and proctitis separately has been the subject of some discussion. In older series, the diseases are combined in which case the incidence in South Asians in Leicestershire would be 14.3 cases $/ 10^{5}$ year from 1972 to 1980 and $13 \cdot 1$ cases/10 $/$ year from 1981 to 1989.

This is one of the largest studies of the incidence of UC, investigating 1420 cases of UC and proctitis (Table V). The standardised incidence of UC in Europeans in the city may be increasing, but in the county as a whole is constant $\left(4 \cdot 1\right.$ cases $/ 10^{5} /$ year $)$. The standardised incidence of proctitis was 2 cases $/ 10^{5} /$ year in Europeans. The mean combined incidence was 
$6 \cdot 1$ cases $/ 10^{5} /$ year which is similar to other series in which UC and proctitis are combined. ${ }^{13-5}$ 7-8

The disease distribution was similar in Europeans and South Asians, however the resection rate was significantly less. A recent study has shown the problems and anxieties related to stomas and surgery of South Asians and Europeans are similar, ${ }^{37}$ there is little to suggest that South Asian patients would refuse surgery more often than Europeans. Together these findings lend support to the suggestion that UC may be less severe in South Asians or that patients are more likely to seek medical advice for mild disease. If this is true it could mean that the difference in incidence is apparent rather than real.

There was a bimodal age distribution in Europeans but not in South Asians. Others have found a similar distribution in Europeans. ${ }^{1-3}$ The age specific incidence was significantly raised in young adult Europeans and South Asians and in elderly Europeans, in whom the age specific incidence was highest.

There is no evidence of an urban-rural gradient in incidence. The definition of urban areas used is similar to other studies. ${ }^{38}$ However, most series have reported a higher incidence in urban than rural areas. ${ }^{2689}$ The lack of difference in the present study may reflect the fact that many people who live in rural Leicestershire commute daily to larger towns for their work and are exposed to urban living conditions.

Reports from Asia suggest that UC is uncommon. ${ }^{11-16}$ However, it may be masked by amoebiasis or other infections. Khosla ${ }^{17}$ has shown recently that the prevalence of UC in Northern India is $43 / 10^{5}$ for men and $48 / 10^{5}$ for women and is comparable with European studies. Anita $e t a l,{ }^{39}$ in a study of patients treated in a private clinic, suggested that Hindus were at greater risk than Muslims. In probably the best study from the region, Al-Nakib et al ${ }^{15}$ reported that the incidence of UC in Kuwait was $2 \cdot 3 / 10^{5} /$ year (based on 91 cases) and that of Crohn's disease was $0 \cdot 5 / 10^{5} /$ year ( 14 cases). UC followed

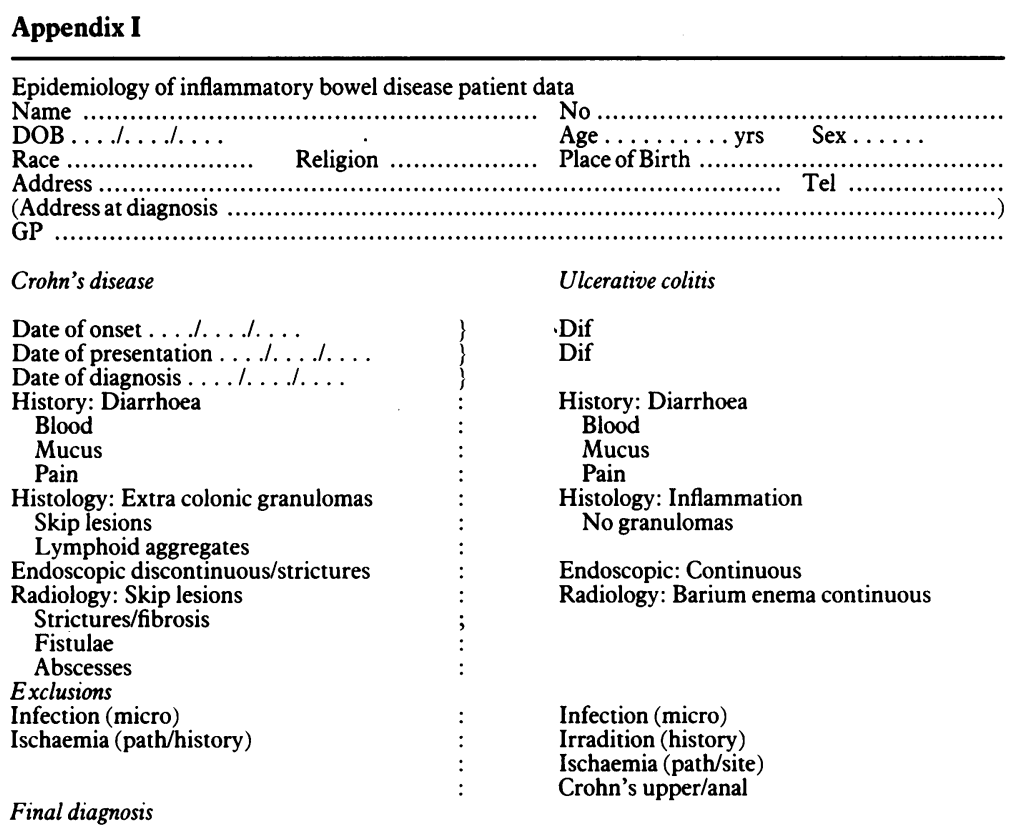

a mild course. Studies of South Asians in Britain have suggested that the prevalence of $\mathrm{UC}$ is comparable with Europeans, ${ }^{2122}$ with a value from Bradford of 59/10 ${ }^{5}{ }^{21}$

All but 24 of the 2500 potential cases of inflammatory bowel disease were reviewed. The addition of these cases, $20 \%$ of whom would have been diagnosed before 1972 or miscoded (and therefore not inflammatory bowel disease), would yield nine additional cases of Crohn's disease, eight of UC, and two of proctitis. All 24 were European. This would increase the incidence by $1.7 \%$ in Europeans. Such a change would not be significant and would not substantially alter the relative risk to South Asians. The use of records from three different hospital departments, consultants with an interest in inflammatory bowel disease, and community resources such as general practitioners and private practice should mean that the incidence reported in the community is reasonably accurate, particularly as inter- and intraobserver variation were both low in the present study.

Community based studies have shown that Muslims (16\%) are twice as likely to smoke tobacco as Hindus $(8 \%) .^{+0}$ Non-smoking is risk factor for UC in Europeans $\mathrm{s}^{33+1}$ and this may partly explain the greater risk to Hindus.

South Asians in Leicestershire have twice the risk of UC than Europeans. The risk is greatest in Hindus and Sikhs in whom the incidence is one of the highest in the world and much greater than that thought to exist in South Asians before migration. The explosion of cases amongst Sikhs is particularly surprising. Further studies in South Asians may show specific environmental factors in the aetiology of ulcerative colitis.

We thank the British Digestive Foundation and the National Association for Crohn's and Colitis who supported Dr V Jayanthi during this programme and the Hilden Trust who provided similar support for Dr C Probert. We thank Dr R G Newcombe, Senior Lecturer in Computing and Medical Statistics, University College of Wales and Professor F Clarke, Department of Community Health, University of Leicester for their advice. We acknowledge the contributions of Dr K Sher, Mr B Bhamra, and Ms P Bhakta in population analysis and thank them for their help. We also thank the consulants, cons records staff in Leicester, Birmingham, Burton on Trent, Coventry, Derby, Grantham, Kettering, Nuneaton, Nottingham,
Oxford, Peterborough, and Rugby.

1 Evans JG, Acheson ED. An epidemiological study of ulcerative colitis and regional enteritis in the Oxford Area. Gut 1965; 6: colitis and

2 Sinclair TS, Brunt PW, Mowat NAG. Natural history of proctocolitis in the North-east of Scotland: a community study. Gastroenterology 1983; 85: 1-11.

3 Morris T, Rhodes J. Incidence of ulcerative colitis in the Cardiff region 1968-1977. Gut 1984; 25: 846-8.

4 Jones HW, Grogons J, Hoare AM. An audit of ulcerative colitis in a district general hospital. Gut 1985; 26: A1123.

5 Binder V, Both H, Hansen PK, Hendriksen C, Kreiner S, Torp-Pedersen $\mathrm{K}$. Incidence and prevalence of ulcerative colitis and Crohn's disease in the County of Copenhagen 1962-1978. Gastroenterology 1982; 83: 563-8.

6 Daiss W, Lorenz-Meyer K. Epidemiology of inflammatory bowel disease in the County of Tubingen (West Germany). Scand 7 Gastroenterol 1989; 24 (suppl 170): 39-43.

7 Ekbom A, Helmick C, Zack M, Adami H-O. The epidemiology of inflammatory bowel disease: a large, population-based of inflammatory bowel disease: a large, population-

8 Bjornsson S. Inflammatory bowel disease in Iceland during a 30 year period, 1950-79. Scand $\mathcal{F}$ Gastroenterol 1989; 24 30 year period, 1950

9 Shivananda S, Pena AS, Mayberry JF, Ruitenberg EJ, Hoedemaeker PJ. Epidemiology of Protocolitis in the Region of Leiden, The Netherlands. Scand $\mathcal{F}$ Gastroenterol 1987; 22: 993-1002.

10 Nordenvall B, Brostrom O, Berglund M, Monsen U, Nordenstrom J, Sorstad J, et al. Epidemiology of ulcerative colitis in Stockholm County. Scand F Gastroenterol 1985; 20: 783-90

11 Tandon BN, Mathur AK, Mohapatra LN, Tandon HD, Wig $\mathrm{KL}$. A study of the prevalence and clinical pattern of non- 
specific ulcerative colitis in Northern India. Gut 1965; 6: 448-53.

12 Chuttani HK, Nigam SP, Sama SK, Dhanda PC, Gupta PS Ulcerative colitis in the Topics. BMF 1967; 4: 204-7.

13 Mir-Madjlessi SH, Forouzandeh B, Ghadimi R. Ulcerative colitis in Iran; A review of 112 cases. Am $\mathcal{F}$ Gastroenterol 1985; 80: 862-6.

14 Sharma MP, Sarin SK. Ulcerative colitis in a Northern Indian Hospital: Current Trends. $\mathcal{F} R$ Coll Physicians 1985; 19: 99 102.

15 Al-Nakib B, Radhakrishnan S, Jacob GS, Al-Lidawi H, AlRuwaih A. Inflammatory bowel disease in Kuwait. $A m \mathcal{F}$ Gastroenterol 1984; 79: 191-4.

16 Probert CSJ, Mayberry JF, Mann R. Inflammatory bowel disease in the rural Indian Subcontinent: A survey of patients attending mission hospitals. Digestion 1990; 47: 426 .

17 Khosla SN. Ulcerative colitis in India. In: Abstracts of the World Congress of Gastroenterology. Sydney 1990. Abingdon: The Medicine Group (UK), 1990: 576

18 Haskey J. The ethnic minority populations of Great Britain estimates by ethnic group and county of birth. Popul Trend 1990; 59: 35-8.

19 Carey S, Shukur A. A profile of the bangladeshi community in East London. New Community 1985; 12: 405.

20 Ballard R, Ballard C. The Sikhs: The development of South Asian settlements in Britain. In: Watson JL, ed. Between two cultures. Blackwell: Oxford, 1977.

21 Findley JM, Jayartne SD. Chronic inflammatory bowel disease in the Asian community of Bradford. In: McConnell $\mathrm{R}$, Rozen P, Langman MJS, Gilat T, eds. The genetics and epidemiology of inflammatory bowel disease. Basel: Karger 1986.

22 Swarbrick ET, Montgomery RD, Dykes PW, Grace RH Lloyd JA, Allan RN. Non-specific inflammatory bowel disease in immigrants: incidence and prevalence in the Midlands. Gut 1984; 25: A1144.

23 Keshavarzian A, Gupta S, Saverymuttu SH, Hodgson HJF Are there ethnic differences in inflammatory bowel disease? Indian 7 Gastroenterol 1986; 5: 95-7.

24 Das SK, Montgomery RD. Chronic inflammatory bowel disease in Asian immigrants. Practitioner 1978; 221 : 747-9.

25 Marett V. Immigrants settling in the city. Leicester: Leicester University Press, 1989.
26 Survey of Leicester 1983. Leicester City Council \& Leicestershire County Council.

27 Office of Population Censuses and Surveys. The Registrar Generals Statistical Review of England and Wales 1971 London: HMSO, 1971.

28 Office of Population Censuses and Surveys. 1981 OPCS Census County Reports Leicestershire. London: HMSO,

29 Leicester Council for Community Relations Annual Report 1982.

30 Leicestershire County Council. Monitoring Bulletin No 55 1990.

31 Nicholl A, Basett K, Vlijaszek SJ. Whats in a name? Accuracy of using surnames and forenames in ascribing Asian ethnic identity in English populations. $f$ Epidemiol Community Health 1986; 40: 364-8.

32 Donaldson LJ, Taylor JB. Patterns of Asian and non-Asian morbidity in hospitals. BMF 1983; 286: 949-51.

33 Logan RFA, Somerville KW, Edmond M, Langman MJS Smoking and inflammatory bowel disease. In: McConnell $R$ Rozen P, Langman M, Gilat T, eds. The genetics and epidemiology of inflammatory bowel disease. Basel: Karger, epider.

34 Cretser GA. Intermarriage between white Britons and immigrants from the New Commonwealth and Pakistan. Fournal of comparative family studies 1990; $21: 227-38$.

35 Armitage $\mathbf{P}$, Berry G. Statistical methods in medical research Oxford: Blackwell, 1988: 115-20, 380-3, 400-5.

36 Gardner MJ, Altman DG, eds. Statistics with confidence. London: British Medical Journal, 1989.

37 Bhakta P, Probert CSJ, Jayanthi V, Mayberry JF. Stoma A579.

38 Mayberry JF, Rhodes J, Newcombe RG. Crohn's disease in Wales, 1967-76; an epidemiological survey based on hospital admissions. Postgrad Med F 1980; 56: 336-41

39 Anita FP, Kalro RH, Gandhi MK, Desai HG, Jayant K Ulcerative colitis - prevalence in socio-economic groups Indian $\mathcal{F}$ Gastroenterol 1985; 4: 19-20.

40 Ahmed WIU, Kernohan EEM, Baker MR. Alcohol and cigarette consumption among white and Asian genera practice patients. Health Educ $\mathcal{F} 1988 ; 47: 128-9$.

41 Jayanthi V, Probert CSI, Mayberry JF Epidemiology of inflammatory bowel disease. $Q \mathcal{F}$ Med $1991 ; 78: 5-12$. 